\title{
Task-based Approach to Develop Intercultural Communicative Competence in College English Education* $^{*}$
}

\author{
Lingling Cai \\ Foreign Language Department, Sichuan University of Science and Engineering, China \\ Junlu Lv \\ Foreign Language Department, Sichuan University of Science and Engineering, China
}

\begin{abstract}
Intercultural communicative competence (ICC) is a hot topic in foreign language teaching and learning. This paper discusses about task-based approach to develop students' intercultural communicative competence in SUSE English class. In so doing, this paper provides theoretical foundations of concepts about intercultural communicative competence and task-based approach. Meanwhile, this paper describes the feasible tasks used in real class and find it is possible to develop students' intercultural communicative competence in Chinese educational context.
\end{abstract}

Index Terms -intercultural communicative competence, task-based approach, English class

\section{INTRODUCTION}

With the rapid development of world economy and technology, particularly, the acceleration of globalization, people all over the world are largely involved in interactions with different people from diverse cultures. Moreover, the communication and cooperation between China and other countries have tremendously increased since the implementation of "One Belt and One Road" policy. Given the incoming numerous intercultural communications, it is argued that college English education should take the responsibility to equip college students (global village citizens) with intercultural communicative competence (ICC) in the process of their English learning, otherwise students will face unpredictable communicative barriers and misunderstandings during the communication.

However, considering the popularity of English learning and teaching in China, the actual awareness of intercultural communicative competence (ICC) to classroom language teaching and learning has been the subject of very little attention. Regardless of these urgent external requirements, college students to some extent even never hear about ICC let alone learn it from class. Therefore, there is a widely held truth that college English education must integrate with proper content and approaches to cultivate and improve students' intercultural communicative competence.

\section{CURrent Problems of College English Education}

From the view of macrocosmic, although Guidelines on College English Teaching (2017) has clearly pointed out that there are three sets of courses, namely, English for General Purposes, English for Specific Purpose and Intercultural Communication, colleges still lack the detailed normative document to guide college English teaching. As a result, there are fewer specific intercultural communicative class arrangements for college English class, especially colleges of the western provinces in China. (The following statistics is mainly based on Sichuan, Yunan and Guizhou provinces).

TABLE 1.

ICC Class IN COLLEGES

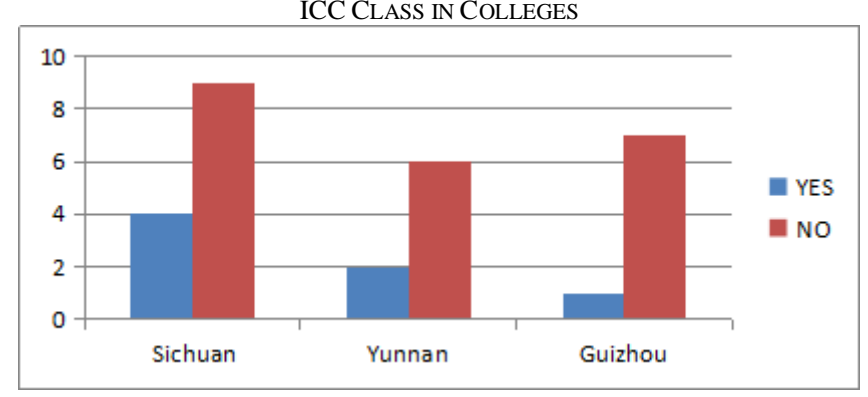

* This study and this paper is supported by SUSE's teaching reform "The Study on Developing Students Intercultural Communicative Competence in College English" ( Number: JG-1860) 
On the basis of the incomplete statistics, it is not difficult to see that fewer colleges have opened this class among the three provinces even including those "Double First Class" colleges. Meanwhile, even colleges have opened it; this class is only aimed at English majors. In addition, colleges also lack the efficient regulation mechanism to control the effects from real class except the only national criterion CET-4 and CET-6, to say nothing of tests about the intercultural communicative competence.

From the view of microcosmic, on one hand, for college English teachers, some of them surely have realized the importance of intercultural communicative competence, while others are not aware of this, which may be illustrated by this following questionnaire and statistics. (In order to make the questionnaire easier be understood, the author only designs five questions and mainly examines teachers' attitude to ICC in class)

\section{Questionnaire (for teachers)}

Please make the judgment as soon as you see the questions and mark the corresponding number before each question: $5=$ totally agree, $4=$ agree, $3=$ not sure, $2=$ disagree, $1=$ totally disagree

\begin{tabular}{|l|ll|}
\hline & 1. & I always implant foreign cultural knowledge in my English class. \\
\hline & 2. & I believe that language points teaching is more important that cultural knowledge. \\
\hline & 3. & I believe that students can communicate with foreigners well after learning this basic cultural knowledge. \\
\hline 4. & I believe that there is of little importance in Chinese culture study in English class. \\
\hline & There are enough materials about ICC in textbooks. \\
\hline
\end{tabular}

The Result from the Questionnaire

\begin{tabular}{|l|l|l|l|l|}
\hline & Largest Value & Smallest Value & Mean & Standard deviation \\
\hline Q1 & 2 & 5 & 4.17 & .747 \\
\hline Q2 & 1 & 5 & 3.02 & 1.330 \\
\hline Q3 & 1 & 4 & 1.80 & .854 \\
\hline Q4 & 1 & 5 & 3.63 & 1.148 \\
\hline Q5 & 1 & 5 & 3.30 & .939 \\
\hline
\end{tabular}

Form the statistics, it is true that over $90 \%$ teachers have paid attention to this problem, but this does not mean teachers will put it into use in class. From the result, it is easy to find that only about $60 \%$ teachers hold that learning cultural knowledge is more important than language points learning so that some teachers still insist on teaching grammar and vocabulary rather than knowledge about ICC. This is well reflected by the real practice in class. (Table 2)

TABLE 2 .

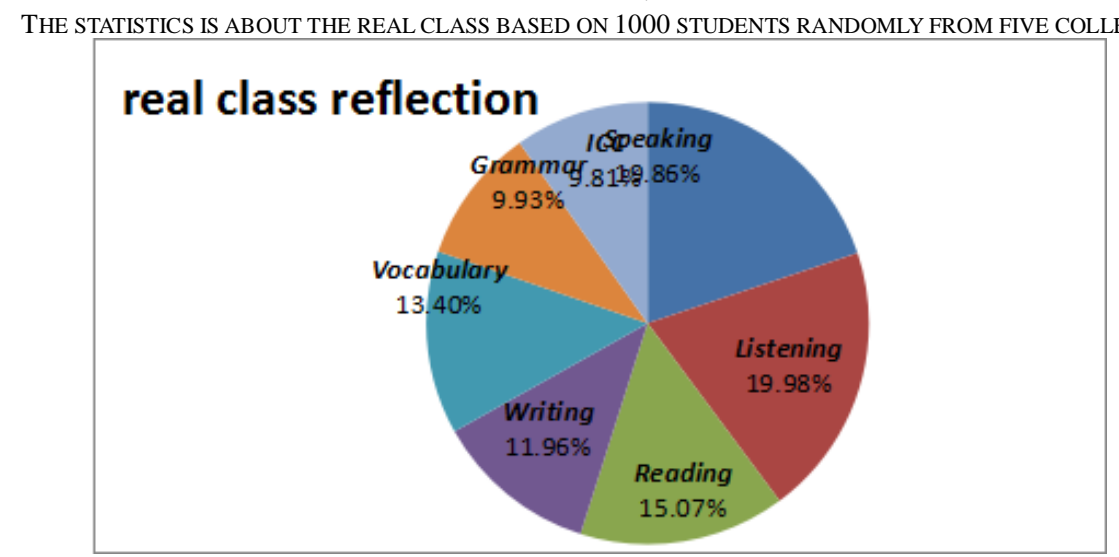

Furthermore, only one third teachers find it is necessary to learn Chinese culture for ICC as well as foreign culture for ICC in class partly because they believe both cultures are the basis for ICC besides those isolated language expressions and usages. Additionally, most of teachers argue that until now there are no suitable books for developing communicative competence.

On the other hand, for most college English learners, intercultural communication learning is not included in their English class as it has been proved in the table 2, which the content about ICC occupies the very small part in the whole class. From Table 2, it can be seen that intercultural learning is solely for English majors and other related majors except college English class. On earth, college students hold what kind of attitude to ICC? (The author also designs five questions and mainly examines students' attitude to ICC.)

\section{Questionnaire (for students)}

Please make the judgment as soon as you see the questions and mark the corresponding number before each question: $5=$ totally agree, $4=$ agree, $3=$ not sure, $2=$ disagree, $1=$ totally disagree 


\begin{tabular}{|l|ll|}
\hline & 1. & I always learn foreign cultural knowledge from my English class. \\
\hline & 2. & I believe that language points teaching is more important that cultural knowledge. \\
\hline & 3. & It is easy to get enough materials from textbooks. \\
\hline & . & I believe that learning foreign culture as well as learning language points. . \\
\hline & 5. & I don't like communicating with foreigners. \\
\hline
\end{tabular}

The Result from the Questionnaire
\begin{tabular}{|l|l|l|l|l|}
\hline & Largest Value & Smallest Value & Mean & Standard deviation \\
\hline Q1 & 1 & 5 & 2.62 & 1.129 \\
\hline Q2 & 1 & 5 & 2.47 & .921 \\
\hline Q3 & 1 & 5 & 3.41 & 1.135 \\
\hline Q4 & 1 & 5 & 4.38 & 1.148 \\
\hline Q5 & 1 & 5 & 2.03 & .827 \\
\hline
\end{tabular}

From the result, firstly, more than $90 \%$ students hope to learn something related to foreign culture and believe that it is useful to communicate with foreigners. In other words, students have strong desire to be good communicator after graduation. Secondly, less than 50\% students admit that they gain little from the English class because traditional teaching still concentrates on language aspects, (speaking, listening reading and writing) and ignore the cultural aspects during the teaching process. Thirdly, contrary to teachers, students hold positive attitude to textbooks so that they can find enough materials from books as well as Internet. Last but not the least; students are not clear about the concept intercultural communicative competence through the learning process

To conclude, despite the great progress about English teaching and learning achieved in the past years, teacher-centered and lacking awareness of intercultural communicative competence still dominate in the class. What's more, there is no consistent culture teaching systematically finished because of the limited class and suitable materials (textbooks). Currently, there is an emergency for colleges to reform English class, though lots of researches have been done to change the present situation, the most feasible way is to transform the teaching method. However, considering these popular teaching methods, the task-based approach can be regarded a good way to change it, which aims to enhance intercultural communicative competence and contribute to a wider educational goal of better understanding the world.

\section{LITERATURE REVIEW}

In order to better carry out the English class reform, it is of necessity to have a good command of the two concepts: intercultural communicative competence and task-based approach.

\section{A. Intercultural Communicative Competence}

The concept "communicative competence" is firstly derived from Hymes (1972), which refers to deal with producing and understanding sentences that are appropriate and acceptable to a particular situation. (Hymes: 1972)) During the 1970s and 1980s, this term has been continuously defined and redefined until Canale and Swain (1980, 1981) provided a new definition about it: it has been defined as a synthesis of an underlying system of knowledge and skill needed for communication.(Canale: 1980) Later, some researchers pointed out that there were five elements in this concept, such as Usó-Juan and Martínez-Flor (2006) pointed out five components: discourse competence, linguistic competence, pragmatic competence, intercultural competence and strategic competence. As it can be noted, this concept has been changed and adapted to the context of its use. What's more, there is an agreement in relation to the truth that a capable language communicator should possess the basic language knowledge as well as the ability and skill to activate the knowledge in the communicative process.

The concept "Intercultural communicative competence" has been widely used and academic researchers have made a consensus on the definition of it. From Byram abroad to Gu Xiaole in China, appropriateness and effectiveness are the indispensable part of the concept. Here are some typical definitions: Chen and Starosta (1998), ICC is depicted as "the ability to effectively and appropriately execute communication behavior to elicit a desired response in a similar way", (Chen and Statosta: 1998 ) Fantini (2006) defines intercultural communicative competence as the complex of abilities needed to perform effectively and appropriately when interacting with others who are linguistically and culturally different from oneself. All in all, the intercultural communicative competence is an ability to achieve the specific goal during the communication process. The most influential model of intercultural communicative competence is based on Byram's analysis, that is, intercultural communicative competence includes attitude, knowledge, skills and critical cultural awareness. (Byram: 1996) Actually, in Byram's view, intercultural communicative competence is a complex phenomenon because each component includes many categories and he combines intercultural communicative competence with the other three competences, which could be well elaborated in the following table 3. 
TABLE 3.

BYRAM'S INTERCULTURAL COMMUNICATIVE COMPETENCE MODEL

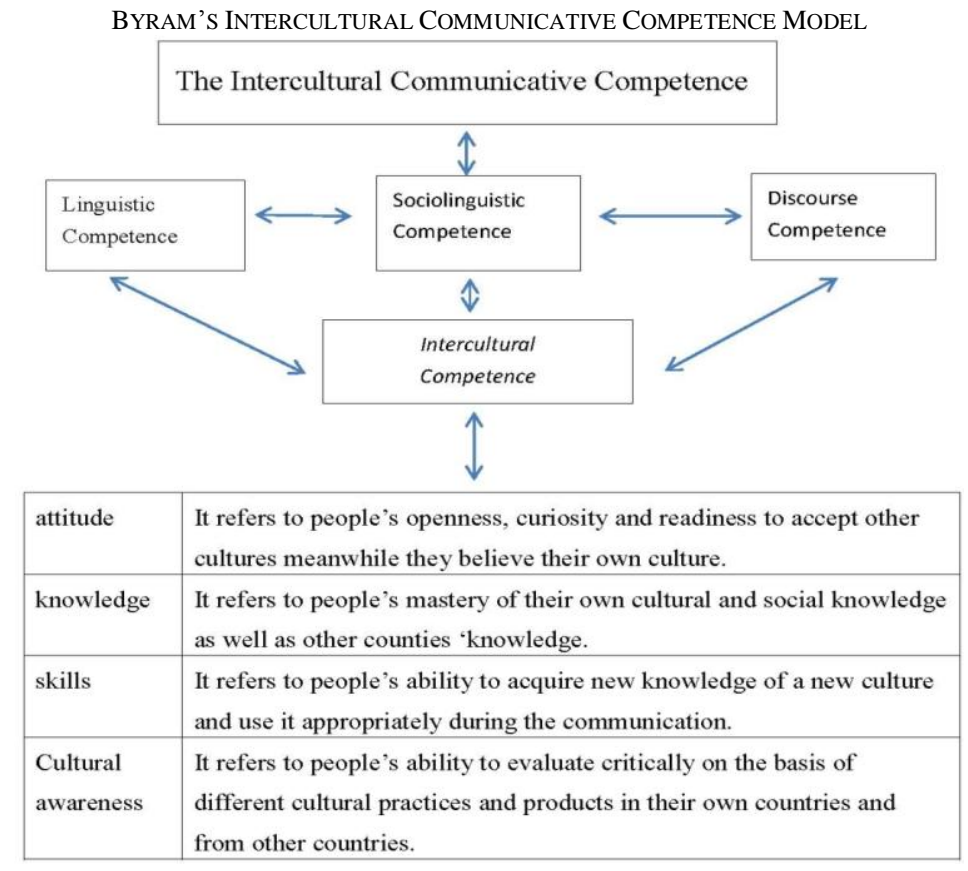

Needless to say, the acquisition of intercultural communicative competence is closely correlated to college English teaching. This model is obviously designed for classroom teaching because this model provides a framework of what intercultural communicative competence needs and what kinds of factors will be taken into account while teaching language. In addition, this model highlights the acquisition of intercultural communicative competence in the educational context and cannot neglect that the linguistic competence is the perquisite for the ICC. In fact, considering the present teaching and learning context, choosing a proper teaching method can make up for it and develop it.

\section{B. Task-based Approach}

There are some popular teaching methods applied in the college English class, such as communicative language teaching approach, situational teaching approach and so on. Most of teachers will first and foremost choose communicative language teaching approach to develop intercultural communicative competence because they believe that intercultural communicative competence emphasizes the ability to communicate with other people from other countries. Actually, this approach to some extent ignores the linguistic competence so that students still lack the basic ability to communicate. Besides, the cultural awareness or cultural values doesn't get enough attentions so that students will not be competent enough to evaluate the situation in which they are in and communicate successfully with other people.

In order to be a competent language user in different cultures, it is necessary to find an integrative approach to combine language learning and culture learning well. That is to say, an approach is helpful to develop intercultural communicative competence through English class. Task-based teaching approach, another efficient teaching method, can be tried in this process. This teaching method was firstly put forward by Prabhu (1987), who argued that it was necessary to have proper activities in real classroom and was related to create conditions for dealing with meanings in classroom. Later, more scholars discussed this approach from different views including Long(1985), Nunan(1989), Willis(1996) ,Skehan(1998) and Ellis(2003). Nunan classified the task into five components: goals, input, procedures, roles and settings. If the intercultural communicative competence learning has been integrated with this approach, teachers need to analyze what kind of goal in the class, what materials needed in the class, what procedures arranged in class, and what roles teachers and students played. Willis's theory is composed of three phrases: pre-task, task-cycle and language focus. Skehan clearly concluded three steps about English class: pre-task, while-task and post-task. (Skehan: 1998) He comprised Willis's theory into his theory, especially, the third phrase into the first one to lay the foundation for students. Ellis argued that English class should have "modified interaction" tasks based on "input and interaction hypothesis", which also pointed out three steps as other in the class. To sum up, common features of task-based approach mainly include: 1) Tasks are designed for finishing those activities with specific purpose through English; one significant feature is that tasks are meaningful and focus on how to express and transfer their thoughts rather than simply on language aspect 2) There is a similarity between people's life and class task, or the class task could be called representation of life. 3) Tasks are complete communicative activities so they can be recycled and repeated in the class until the goal has been reached. What's more, according to these features discussed above, the college English class should follow the four principles when designing the class: the first one is authenticity principle, 
the second one is the form-function principle, the third one is the task dependency and the task chain principle, the fourth one is learning by doing.

\section{STUdy ABout TASKED-BASEd ACTIVITIES USED IN ENGLISH Class}

The former questionnaire to teachers and students revealed their recognition about the fact that the intercultural communicative competence is lacking in the present English class, so based on what has been discussed in the third part, the final study results are derived from teaching dairy (observations of students' behaviors) and interviews plus two tests after task-based approach has be used in the college English class for one term in author's class in SUSE. Surely, this study may contribute to raising the awareness both teachers and students of SUSE and to some extent change the present teaching environment in SUSE.

\section{A. The Preparation of the Study}

The study is based on the experiences, perceptions, opinions and suggestions of both students and professors of SUSE. The study consisted of three main factors 1) the selection of the participants, (2) the selection of textbooks (3) the objectives of this study. The participants are total 198 students from law and chemistry department to take part in English class. These students' academic level is key issue to consider even though the number is a bit large to be observed. All these students have passed CET-4 which means they have the basic knowledge about English learning. Furthermore, they all are willing to join in this study. Concerning the selection of textbooks, New Horizon College English series are adopted in this study, which has been embedded with abundant first-hand materials about foreign cultures. The textbook are compiled corresponding to the basic requirements of the Ministry of Education, which to cultivate students' elementary abilities (speaking, listening, reading and writing) and to develop their intercultural communicative competence for future effective communication. The study differs from that former study which is mainly concerned about language. This objective of this study is summarized as follows: a) to learn intercultural knowledge b) to cultivate intercultural attitude c) to develop intercultural skills. It is easy to find that the three objectives coincide with the basic requirement of intercultural communicative competence and the following study will fulfill the three objectives

\section{B. Tasks Designed in English Class}

After having reviewed some researches on task-based approach, the following tasks are intended to aim students a theoretical insight into the key factors of intercultural communicative competence and culture-related activities and real life situations that could be incorporated into regular lesson designs. In this study, the author has mainly adopted Skehan's model: pre-task, while-task and post-task along with some changes from other researchers. In the following part, the author will explain these tasks in details in order to incorporate with intercultural communicative competence. (The author will list some tasks in one semester because of the limited space available) These tasks fulfil the following requirement: 1) the task is centered on students' intercultural communication needs, interests and experiences; 2) the task is meaningful and help students to raise awareness of their culture and foreign culture; 3) the task will equip students with enough intercultural knowledge and strategies to avoid cultural misunderstandings. These tasks presented in the article are interview, role play, case study, problem-solving, and brainstorming and so on. All of them are communicative, but more than that they are proposed as practical classroom activities tackling issues of intercultural communication in a flexible way.

\section{Task one: Learning intercultural knowledge}

Cultures are different from each other so that students need to accumulate other cultural knowledge as well as own culture in order to make comparisons and contrasts. Sometimes, it is necessary to master some non-verbal behavior knowledge for a smooth communication. (All the materials are from New Horizon English book 2) The following records are from teachers' dairies.

Sample one: Lead-in Part in "Dance with Love"

Teaching contents: introduce the different dating styles in different cultures

Teaching methods: Task-based teaching. There are three parts (pre-task, while-task, post-task)

Teaching activities: 1) brainstorming 2) report (comparison and contrast)

Teaching procedure:

1). pre-task ( the activity is brainstorming)

In this step, teacher firstly introduces the topic "dating" and asks students to preview this topic. Then the teacher divides students into four groups to search enough materials about this topic. During this process, students can use internet to gain information or ask teacher to help. In this step, teacher need to tell students that dating is a universal topic but students should be cautious about something related to foreigners' privacy and avoid some misunderstandings during communication.

Response: students conclude that there are four dating types: online dating, speed dating, formal dating and casual dating. Here is a new dating style in China, such as TV dating. They also record what kind of dating style is more popular among young people.

2). While-task (the activity is pretention, questionnaire and problem-solving) 
In this step, teacher firstly comment students' findings and tells students that TV dating is also popular in England and America; for example, the program "take me out" in London is also hot. Then the teacher encourages students to do comparison and contrast between China and foreign countries' dating ways. Students need to care about the two questions 1) who should first initiate the date? 2) Who should pay for the date?

Response: After four groups' presentations, students have a command of knowledge about dating and they even talk about the different marriage concepts between China and other countries. During this process, students surprisingly find out some facts are totally different from their original imagination. (this represents a little progress in intercultural awareness) Thus, it will definitely help their future communication.

3). Post-task

In this step, teacher evaluates students' work and supplements intercultural knowledge to students. Then, ask students to write a report about a film about Chinese marriage or foreign one.

2. Task two: cultivating intercultural attitude

Intercultural attitude, which will influence the communication, cannot be built in one day or one year so it needs a long time to build through materials learning and involvement in lots of practice. Intercultural attitude refers to the attitude that people hold towards to someone with different values, conventions, customs and practices. For intercultural attitude, the primary is to cultivate curiosity and openness to foreign culture. The second is to acknowledge the difference and eliminate prejudice. (All the materials are from New Horizon English book 2) The following records are from teachers' dairies.

Sample two: Lead-in Part in "The Money Game"

Teaching contents: introduce different values to money between Chinese and Americans

Teaching methods: Task-based teaching. There are three parts (pre-task, while-task, post-task)

Teaching activities: 1) brainstorming 2) report (comparison and contrast) 3) Role-play

Teaching procedure:

1) Pre-task ( the activity is brainstorming and questionnaire)

In this step, the teacher firstly helps students to learn vocabulary about money. This step is crucial for students to have valid communication especially the topic are fresh for them or else it will hinder the effective communication. Then, teacher can ask students one question "How will you budget your money?" "How will you be a smart consumer?" Actually, students will find it hard to answer because they think this question somewhat interfere in their privacy. Meanwhile, they are doubtful whether foreign students will answer these questions. Surely, it is impolite to ask foreigners about this kind of question when people meet each other for the first time. However, students may ask foreigners' permission to finish the task and they are also curious about their peer's attitude to money (credit card). Here is the supplementary of language focus: Max out credit card; Money is tight. Someone is short on cash. Activate card. Run the card through. etc.

Response: Students gradually learn to communicate friends home and abroad and at the same time they change their attitude to other people. They are willing to share their experience with each other.

2) While-task(the activity is interview and problem-solving)

In this step, teacher encourages students to present their statistics about their questionnaire. They find the similarities and differences between Chinese students and foreign students' consuming habits as well as their credit card situation. In this step, students make interviews with each other to answer questions and record their behavior as well.

Response: Students are excited to finish this task and surprised to find that Chinese students and foreign students have more in common than before. To their surprise, they once again change their attitude to foreign culture following the learning process.

3) Post-task

In this step, students are required to finish a communicative activity. They choose different roles to play and face the same question (they have maxed out their credit card). Then what will happen? Who will they give a call firstly?

3. Task three: developing intercultural skills

Intercultural skills include many aspects: the first is to be brave enough to deal with culture shocks; the second is to be capable of consider other people's situation; the third is to be flexible to adapt their non-verbal behavior and verbal behavior; the last is to be adept at learning new culture and so on. (All the materials are from New Horizon English book 2) The following records are from teachers' dairies.

Sample three: Lead-in Part in "Language in mission"

Teaching contents: learn to give negative response

Teaching methods: Task-based teaching. There are three parts (pre-task, while-task, post-task)

Teaching activities: 1) brainstorming 2) report (comparison and contrast) 3 ) opinions-exchange

Teaching procedure:

1) Pre-task

The teacher firstly tells students that the task is to train their conversational skills on the topic "language learning". They focus on "making inquiries and "giving negative response". Of course, Chinese people and people from English-speaking countries have different expressions due to their thinking patterns. As is known to all, making inquiries is the usual verbal goal during conversation. The teacher requires students to make dialogues while using 
“"'making inquiries and "giving negative response". There are two basic types of inquiries: one is to make request, the other one is get other people's opinion.

Response: Students at first are not aware of differences between Chinese expression and foreign expression so that they use Chinese way to express. Moreover, they don't realize that this also will influence communication.

2) While-task (activities: brainstorming, role-play)

Students firstly brainstorm some related expressions and words about the negative response such as: "No, I don't agree." "No, I don' think so." "I'd rather not..." "I don't feel like..." and so on. From these expressions, it can be seen that our Chinese way is more direct on this aspect compared with foreign ones. Here are some examples made by students:

a) A: Will you tell me the whole process?

B: I'd rather not tell you.

b) A: People say the language is difficult to learn, what would you say?

B: I'm afraid that' not true.

c) A: What about going swimming with me?

B: I don't feel like going swimming today.

d) A: Do you mind if I smoke?

B: I'm afraid so.

Students make out four dialogues in which a) and c) are nonsense even though they sound good and use negative response. Moreover, making negative response doesn't mean use negative expression or vocabulary; on the contrary, it even adopts positive expression like the sentence in d) dialogue.

Response: Students actively join the study and find some mistakes that they have never paid attention before. What' more, students find team work is more efficient in this process.

3) Post-task

In this step, the teacher asks students to review this topic again and learn to express positive models at their spare time. At the same time, students need develop intercultural communicative competence in this process.

\section{Analysis of This Study after One Semester}

In this semester, the study indeed arouses students' interest in English learning and helps them to learn something related to intercultural communicative competence. However, Intercultural communicative competence cannot be separated and the three components of it are closely integrated. There is no doubt that intercultural knowledge and intercultural attitude are prerequisite for intercultural skills. Only if the students take positive attitude and gain enough intercultural knowledge, can intercultural skills be enhanced. During the study, it is not difficult to find that the other two components are also involved in the process even though one of the components has been stressed in one lesson. To sum up, the three components are intertwined with each other to develop intercultural communicative competence.

Before doing this study, the author has provided two intercultural communicative competence tests respectively to record the original level of students' intercultural communicative competence and changed level after one semester training. These tests are transformed from "Culture Test Model" put forward by Valette (1977) which is composed three parts: five questions about non-verbal behavior, five questions about verbal behavior, and five questions are open-ended questions. (the questionnaire can be seen in the Appendix) This result will be analyzed here to verify one truth that students have slightly changed after the task-based teaching method has been adopted in English class. To be exact, students' communicative skills haven't changed a lot, but intercultural knowledge and intercultural attitude have been improved slightly after the semester study, which can be proved in the next table.

TABLE 4

PAIRED SAMPLES STATISTICS OF INTERCULTURAL KNOWLEDGE OF BEFORE AND AFTER THE STUDY

\begin{tabular}{|l|l|l|l|l|}
\hline & Mean & N & Std. Deviation & Std. Error Mean \\
\hline Pre-test & 3.7798 & 60 & 1.6732 & .20643 \\
\hline Post-test & 4.5094 & 60 & 1.4456 & .19734 \\
\hline
\end{tabular}

From the table, it can be seen that the mean score has increased after the study and the standard deviation has decreased after the study. It indicates that students' intercultural knowledge has improved and the individual's difference has been narrowed down after on semester. Besides, students become braver to confront obstacles during communications and gradually become a mature communicator.

\section{SUMMARY}

This paper focuses on the study of developing intercultural communicative competence through English class. Firstly, in this study, the teacher adopts the task-based approach to specify the learning objectives in each class and stresses the input of intercultural knowledge. Through the study, it is feasible to for English teachers to implement culture learning in the Chinese foreign language educational context. Secondly, the English language proficiency of students has also been improved rather than lowered as some teachers expect before the study. In this study, the motivation of students has been aroused and the four basic language skills have been well integrated into this process. For most students, they 
acquire more language knowledge than the traditional way of teaching. Lastly, the teacher needs to be patient to students' progress because students need a long time to acquire the details and need a real situation to testify their ability.

\section{ApPendix A. Intercultural Communicative Competence Test (Pre-test)}

The test is used about the level of the college students' intercultural communicative competence. Thank you for your participation.

I. In this part, there are ten multiple choice. You can choose the right answer from the three or four choices.

1. In the west, bats are considered be to

$\begin{array}{ll}\text { A. A sign of fortune } & \text { B. a sign of misfortune }\end{array}$

$\begin{array}{ll}\text { C. A sign of happiness } & \text { D. a sign of high score }\end{array}$

2. Robben Island is a( an )

$\begin{array}{lll}\text { A. Park } & \text { B. prison } & \text { C. hospital }\end{array}$

3. is not Jack London' work.

$\begin{array}{ll}\text { A. White Fang } & \text { B. The Million Pound Note C. The Call of the Wild }\end{array}$

4. What does an owl mean?

$\begin{array}{lll}\text { A. A wise guy } & \text { B. the sign of bad luck C. the sign of good luck }\end{array}$

5. Can you tell us the capital of U.S.A?

A. New York B. London C. Washington

6. ----How are you doing?

A. I'm writing a letter to my parents.

B. Very well, thank you.

C. That' great.

D. Not at all.

7. ----I'm sorry. I forget to leave my email address.

A. Well, it's OK. B. No, it's all right.

C. You are welcome. D. You are wrong.

8. On the way to school, you greet your teacher, "_ "

$\begin{array}{ll}\text { A. Good morning, teacher } & \text { B. Good morning, Mr Smith }\end{array}$

B. Hi, Mr Smith. Where are you going?

9. Usually American has orange juice, ham, and scrambled eggs for breakfast.

A. I agree B. I don't think so C. I'm not sure

10. What should you say, when a native English speaker express his gratitude?

A. No, it is nothing. B. I am glad to be of help. C. Not at all

II. Open Questions:

1. What is your impression about British and American people?

2. Do you have any interests in west culture?

3. We often hear that western culture is more superior to Chinese one. What do you think of it?

4. Do you have confidence in communicating well with foreigners?

5. Do you think that English class is helpful for your future communication?

\section{ApPendix B. InTERCultural Communicative Competence Test (Post-Test)}

The test is used about the level of the college students' intercultural communicative competence. Thank you for your participation.

1. The Bible was originally written in
A. Latin
B. English
C. Hebrew
D. Arabic

2. "Crossing one's forefinger and middle finger" signifies in English speaking countries.

A. Good luck B. sadness C. respects D. secretary

3. In business English " in the blank" means

A. Running a business with no money

B. running a business with bad fortune

C. Running a business profitable

D. Running a business at a loss

4. When English speakers part, they usually say

A. So long B stay here please C. walk well, please D. see you later

5. In English culture "white" connotes

$\begin{array}{llll}\text { A. Death } & \text { B. cruelty } & \text { C. reaction D. innocence }\end{array}$ 
6. Usually American has orange juice, ham, and scrambled eggs for breakfast.

$\begin{array}{lll}\text { A. I agree B. I don't think so C. I'm not sure } & \text { B. }\end{array}$

7. What should you say, when a native English speaker express his gratitude?

A. No, it is nothing. B. I am glad to be of help. C. Not at all

1. The British English equivalent for “私立学校” is

A. Public school B. council school C. private school D. grade school

2. In British English, to gain the attention of a stranger, speaks often rely on

A. Excuse me B Hello C Miss/MR D Hi

10. What should you say, when a native English speaker express his gratitude?

A. No, it is nothing. B. I am glad to be of help. C. Not at all

II. Open Questions:

1. What is your impression about British and American people?

2. Do you have any interests in west culture?

3. We often hear that western culture is more superior to Chinese one. What do you think of it?

4. Do you have confidence in communicating well with foreigners?

5. Do you think that English class is helpful for your future communication?

\section{REFERENCES}

[1] Byram, M. (1997). Teaching and Assessing Intercultural Communicative Competence. Clevedon, Avon, UK: Multilingual Matters.

[2] Byram, M. \& Zarate, G. (1997). The Sociocultural and Intercultural Dimension of Language learning and Teaching. Strasbourg Cedex: Council of Europe Publishing,

[3] Canale, M.and Swain, M. (1980). Theoretical Bases of Communicative Approaches to Second Language Teaching and Testing. Applied Linguistics, 1(1):1-47, 8-24

[4] Chen, G-M. and Starosta, W. J .( 1998). Foundations of Intercultural Communication. Allyn and Bacon. USA.

[5] Ellis, R. (2003). Task-based Language Learning and Teaching. Oxford: Oxford University Press.

[6] Fantini, A. E. (2006). Assessment Tools of Intercultural Communicative Competence SIT Occasional Paper Series.

[7] Hymes, Dell. (1972). On Communicative Competence. In Pride and Holmes.

[8] http://blog.sina.com.cn/s/blog_71b3fcbe0100nnl5.html ( accessed 20/7/2019).

[9] https://wenku.baidu.com/view/c14868001fd9ad51f01dc281e53a580216fc50b5.html (accessed 20/7/2019).

[10] Long, M. W. (1985). Modeling and Assessing Second Language Acquision. Clevedon Avon: Multiligual Matters Ltd.

[11] Nunan, D. (1989). Designing Tasks for Communicative Classroom Cambridge: Cambridge University Press.

[12] Nunan, D. (2004). Task-based language Teaching Cambridge: Cambridge University Press.

[13] Prabhu, N.S. (1987). Second Language Pedagogy: A Perspectieve. Oxford: Oxford University Press.

[14] Samovar,L.A.,and Porter,R.E. (1997). Intercultural Communication: A reader (8:th Ed.).Belmont, Ca: Wadsworth Publishing company.

[15] Skehan, P. (1996). A Framework for the Implementation of Task-based Instruction. Applied Linguistic, 17(1): 47-49

[16] Skehan, P. (1998). A Cognitive Approach to Language Learning. Shanghai: Shanghai Foreign Language Education Press.

[17] Valette,R.M. (1977). Modern Language Testing New York: Harcourt, Brace, Jovanovich.

[18] Willis, J. (1996). A Framework for Task-based Learning. London: Longman.

[19] Wen Qiufang.(2004). Research Methods and Thesis Writing. Beijing: Foreign Language Teaching and Research Press.

Lingling Cai was born in Sichuan, China. She received her Master degree in European Culture from Sichuan University, China in 2011. She is currently an associate professor in the School of Foreign languages, Sichuan University of Science and Engineering, Zigong, Sichuan, China. Her research interests include intercultural communication and literature study.

Junlu Lv was born in Sichuan, China. He is currently an associate professor in the School of Foreign languages, Sichuan University of Science and Engineering, Zigong, Sichuan, China. His research interests include intercultural communication and second language teaching 